\title{
Blending of Genetic Algorithm with Fletcher Reeves Method to Solve Reactive Power Problem
}

\author{
K. Lenin, B.R. Reddy, and M.S. Kalavathi
}

\begin{abstract}
In this study a hybrid algorithm - Fletcher Reeves method and advanced Genetic Algorithm (GA) are suggested to solve reactive power problem. In this approach, each of the $G$ Fletcher Reeves method again with progressive operators are calculated step length. These approaches are extended to a set of multi-point access instead of single point approximation to avoid the convergence of the available method at local optimum and a new method, named Population Based Fletcher Reeves Method (PFR), are proposed to solve the reactive power problem. PFR was tested in standard IEEE 30 bus test system and simulation results demonstrate obviously about the best performance of the recommended algorithm in reducing the real power loss with control variables within the limits.
\end{abstract}

Index Terms-Hybrid Algorithm, Fletcher Reeves method, Genetic Algorithm, Bound Constrained Optimization problem, Global-optima, optimal reactive power, Transmission loss.

\section{INTRODUCTION}

$\mathrm{T}_{\mathrm{s}}^{\mathrm{s}}$ O till date various methodologies has been applied to solve the electrical reactive power problems. The key aspect of solving the reactive power problem is to reduce the real power loss with control variables are within the limits. Previously many type of mathematical methodologies like linear programming, gradient method [1-8] has been utilized to solve the electrical reactive power problem, but they lack in handling the constraints to reach a global optimization solution. In the Next level various types of Evolutionary algorithms [9-20] has been applied to solve the reactive power problem. But every algorithm has some merits and demerits. If one algorithm good in exploration but it lack in exploitation and another algorithm good in exploitation although it lack in exploration. Also some algorithm has poor speed in convergence. In the proposed method the step length of the Fletcher-Reeves method in each iteration is evaluated by GA. The above proposed concept is used to set initial points to overcome the problem of premature convergence. Proposed Population Based Fletcher Reeves Method (PFR) was tested in standard IEEE 30 bus test system and simulation study indicate the best performance of the proposed algorithm.

K.Lenin JNTU, Hyderabad,India , (e-mail: gklenin@gmail.com).

B.R. Reddy, JNTUA, Anantapur University in the field of Electrical Power Systems. (e-mail: bbumanapalli-brreddy@yahoo.co.in)

M.S. Kalavathi, Head of the electrical and electronics engineering department in JNTU, Hyderabad, India (e-mail: munagala.12@yahoo.co.in)

\section{OBJECTIVE FUNCTION}

A. Active power loss

The objective of the reactive power dispatch problem (RPDP) is to minimize the active power loss (APL) and can be defined in equations as follows:

$$
\mathrm{F}=\mathrm{PL}=\sum_{\mathrm{k} \in \mathrm{Nbr}} \mathrm{g}_{\mathrm{k}}\left(\mathrm{V}_{\mathrm{i}}^{2}+\mathrm{V}_{\mathrm{j}}^{2}-2 \mathrm{~V}_{\mathrm{i}} \mathrm{V}_{\mathrm{j}} \cos \theta_{\mathrm{ij}}\right)
$$

Where F- objective function, PL - power loss, gk conductance of branch, $\mathrm{Vi}$ and $\mathrm{Vj}$ are voltages at buses $\mathrm{i}, \mathrm{j}$, Nbrtotal number of transmission lines in electric power systems.

\section{B. Voltage profile improvement}

To minimize the voltage deviation in PQ buses, the objective function can be written as:

$$
\mathrm{F}=\mathrm{PL}+\omega_{\mathrm{v}} \times \mathrm{VD}
$$

Where, VD - voltage deviation, $\omega_{\mathrm{v}}$ - is a weighting factor of voltage deviation.

And the Voltage deviation given by:

$$
\mathrm{VD}=\sum_{\mathrm{i}=1}^{\mathrm{Npq}}\left|\mathrm{V}_{\mathrm{i}}-1\right|
$$

\section{Equality Constraint}

The equality constraint of the problem is indicated by the power balance equation are given below:

$$
P_{G}=P_{D}+P_{L}
$$

Where the total power generation PG has to cover the total power demand PD and the power losses PL.

\section{Inequality Constraints}

The inequality constraint implies the limits on components in the power system in addition to the limits created to make sure system security. Upper and lower bounds on the active power of slack bus $(\mathrm{Pg})$, and electrical reactive power of generators $(\mathrm{Qg})$ are written as follows:

$$
\begin{gathered}
\mathrm{P}_{\text {gslack }}^{\min } \leq \mathrm{P}_{\text {gslack }} \leq \mathrm{P}_{\text {gslack }}^{\max } \\
\mathrm{Q}_{\mathrm{gi}}^{\min } \leq \mathrm{Q}_{\mathrm{gi}} \leq \mathrm{Q}_{\mathrm{gi}}^{\max }, \mathrm{i} \in \mathrm{N}_{\mathrm{g}}
\end{gathered}
$$

Higher and lower bounds on the bus voltage magnitudes: 


$$
\mathrm{V}_{\mathrm{i}}^{\min } \leq \mathrm{V}_{\mathrm{i}} \leq \mathrm{V}_{\mathrm{i}}^{\max }, \mathrm{i} \in \mathrm{N}
$$

Higher and lower bounds on the transformers tap ratios:

$$
\mathrm{T}_{\mathrm{i}}^{\min } \leq \mathrm{T}_{\mathrm{i}} \leq \mathrm{T}_{\mathrm{i}}^{\max }, \mathrm{i} \in \mathrm{N}_{\mathrm{T}}
$$

Higher and lower bounds on the compensators it can be expressed by the following equation.

$$
\mathrm{Q}_{\mathrm{c}}^{\min } \leq \mathrm{Q}_{\mathrm{c}} \leq \mathrm{Q}_{\mathrm{C}}^{\max }, \mathrm{i} \in \mathrm{N}_{\mathrm{C}}
$$

Where $\mathrm{N}$ is the total number of buses, NT is the total number of Transformers; $\mathrm{Nc}$ is the total number of shunt reactive compensators.

\section{FLETCHER-REEVES METHOD}

The well-known Fletcher -Reeves method is steepest descent method due to Cauchy is one of the oldest for solving unconstrained minimization problem [21]. In Fletcher- Reeves method, the key task is to find the optimal step length for getting the next better approximations of the decision variables in each iteration. Nearly all the scholars around the world utilized this approach in various applications. Here we are going to blend Genetic algorithm with Fletcher-Reeves to solve the reactive power problem.

\section{GENETIC AlgORITHM}

Genetic algorithms (GA), the most widely used unique method used in the solution of many problems. To unravel an optimization problem through GA, it is very obligation to plan a suitable chromosome representation of solution. There are dissimilar types [22.23] of acting between which binary and real coding representations are common. In binary coding demonstration each changeable is characterized as binary substrings with ideal precision. In this instance the string length of an isolated will be huge and GA would execute In the following sections. In real coding exemplification all chromosome vectors are encoded as a vector of floating point number of same length as the solution vector. This category of illustration is very elementary to handle and is proficient of representing very quiet large domains. In this exemplification a vector $\left(\mathrm{x}_{1}, \mathrm{x}_{2}, \ldots, \mathrm{x}_{\mathrm{n}}\right)$ is used as a single to represent a solution of the optimization problem. In the subsequent step is to initialize the chromosomes which will take part in the artificial genetic operations like natural genetics. In this way population size of chromosomes are formed in which each element is initially selected arbitrarily within the desired domain. Amongst many processes for selection of an arbitrary number, here we have used the uniform distribution method.

\section{POPUlation BASED FlETCHER-REEVES METHODOLOGY FOR SOLVING RECATIVE POWER PROBLEM}

In this paper, a new methodology population based Fletcher Reeves method (PFR) by extending the inkling of single-point exploration to a multi-point exploration. The multiple approximations produce a series of paths among which at least one converges to the global optimum. In this technique of the study, all the chromosomes is upgraded by Fletcher Reeves method whereas the step length is calculated by GA. Algorithm

Step-1: Set $k=0$

Step -2: produce an initial population $x^{(k)}$, by generating each component $\quad x_{i}^{(k)}\left(i=1,2, \ldots, p_{-}\right.$size $)$. (P_size denotes population size)

Step -3: Compute the function values $f\left(x_{i}^{(k)}\right)$ for all $i$

Step -4: Find the best value of $f$ from all $f\left(x_{i}^{(k)}\right)$ come along with $x^{(k)}$ and keep it in $f_{\text {old }}^{(k)}$ and $x_{\text {old }}^{(k)}$

Step-5: Increase the value of $k$ by unity i.e., $\mathrm{k}=\mathrm{k}+1$

Step-6: Set $\mathrm{i}=1$,

Step-7: Find the search direction $d_{i}^{(k-1)}=-\nabla f\left(x_{i}^{(k-1)}\right)$

Step-8: Find the best found value of step length $\lambda$ and store this value in $\lambda_{i}^{(k-1)}$

Step-9: Compute $x_{i}^{(k)}=x_{i}^{(k-1)}+\lambda_{i}^{(k-1)} d_{i}^{(k-1)}$

Step-10: Compute $d_{i}^{(k)}=-g_{i}^{(k)}+\beta_{i}^{(k-1)} d_{i}^{(k-1)}$, Where;

$\beta_{i}^{(k-1)}=\frac{\left\langle g_{i}^{(k)}, g_{i}^{(k)}\right\rangle}{\left\langle g_{i}^{(k-1)}, g_{i}^{(k-1)}\right\rangle}$ and $g_{i}^{(k)}=\nabla f\left(x_{i}^{k}\right)$

Step -11: Compute the best found value of step length $\lambda_{i}^{(k)}$

Step-12: Improve the solution $x_{i}^{(k+1)}=x_{i}^{(k)}+\lambda_{i}^{(k)} d_{i}^{(k)}$

Step -13: Compute $f\left(x_{i}^{(k+1)}\right)$

Step -14: Increase the value of $i$ by unity i.e., $\mathrm{i}=\mathrm{i}+1$

Step -15: if $i=<p_{\text {_ }}$ size, then go to step 7

Step-16: Find the best value of $f$ from all $f\left(x_{i}^{k}\right)$ along with $x_{i}^{k}$ and store it in $f_{\text {new }}^{(k)}$ and $x_{\text {new }}^{(k)}$

Step-17: If the termination criterion is satisfied, go to step-19. Else, go to step-18,

Step $-18: f_{\text {new }}^{(k)}<f_{\text {old }}^{(k)}$, assign $f_{\text {old }}^{(k)}=f_{\text {new }}^{(k)}$ and $x_{\text {old }}^{(k)}=x_{\text {new }}^{(k)}$ and then go to step -5

Step-19: Print the result and stop the process.

\section{Simulation Results}

Validity of PFR algorithm has been verified by testing in IEEE 30-bus system, 41 branch system and it has 6 generator-bus voltage magnitudes, 4 transformer-tap settings, and 2 bus shunt reactive compensators. Bus 1 is taken as slack bus and 2, 5, 8, 
11 and 13 are considered as PV generator buses and others are PQ load buses. Variables limits of the control are shows in Table I.

TABLE I

PRIME VARIABLE LIMITS (PU)

\begin{tabular}{|c|c|c|c|}
\hline List of Variables & Min. & Max. & Type \\
\hline Generator Bus & 0.90 & 1.11 & Continuous \\
\hline Load Bus & 0.91 & 1.01 & Continuous \\
\hline Transformer-Tap & 0.92 & 1.01 & Discrete \\
\hline Shunt Reactive Compensator & -0.10 & 0.30 & Discrete \\
\hline
\end{tabular}

In Table II the power limits of generators buses are listed.

TABLE II

GENERATORS POWER LIMITS

\begin{tabular}{|c|c|c|c|c|}
\hline Bus & Pg & $\mathbf{P g}_{\min }$ & $\mathbf{P g}_{\max }$ & $\mathbf{Q g}_{\min }$ \\
\hline 1 & 96.00 & 49 & 200 & -19 \\
\hline 2 & 79.00 & 18 & 79 & -19 \\
\hline 5 & 49.00 & 14 & 49 & -11 \\
\hline 8 & 21.00 & 11 & 31 & -14 \\
\hline 11 & 21.00 & 11 & 28 & -12 \\
\hline 13 & 21.00 & 11 & 39 & -14 \\
\hline
\end{tabular}

TABLE III

AFTER OPTIMIZATION VALUES OF CONTROL VARIABLES

\begin{tabular}{|c|c|}
\hline $\begin{array}{c}\text { Control } \\
\text { Variables }\end{array}$ & PFR \\
\hline V1 & 1.0501 \\
\hline V2 & 1.0408 \\
\hline V5 & 1.0206 \\
\hline V8 & 1.0305 \\
\hline V11 & 1.0702 \\
\hline V13 & 1.0507 \\
\hline T4,12 & 0.0000 \\
\hline T6,9 & 0.0100 \\
\hline T6,10 & 0.9000 \\
\hline T28,27 & 0.9100 \\
\hline Q10 & 0.1000 \\
\hline Q24 & 0.1000 \\
\hline $\begin{array}{c}\text { Real power } \\
\text { loss }\end{array}$ & 4.2901 \\
\hline $\begin{array}{c}\text { Voltage } \\
\text { deviation }\end{array}$ & 0.9091 \\
\hline
\end{tabular}

Table III shows the proposed PFR approach successfully kept the control variables within limits.

Table IV list out the overall comparison of the results of optimal solution obtained by various methods.

TABLE IV

COMPARISON OF RESULTS

\begin{tabular}{|c|c|}
\hline Techniques & $\begin{array}{c}\text { Real power } \\
\text { loss (MW) }\end{array}$ \\
\hline SGA (24) & 4.9800 \\
\hline PSO (25) & 4.9262 \\
\hline LP (26) & 5.9880 \\
\hline EP (26) & 4.9630 \\
\hline CGA (26) & 4.9800 \\
\hline AGA (26) & 4.9260 \\
\hline CLPSO(26) & 4.7208 \\
\hline HSA (27) & 4.7624 \\
\hline BB-BC (28) & 4.6900 \\
\hline PFR & 4.2901 \\
\hline
\end{tabular}

\section{CONCLUSION}

In this paper, Population Based Fletcher Reeves method is efficaciously applied in order to solve Optimal RPDP. The projected PFR algorithm is tested in the standard IEEE 30 bus system operators. Simulation results show the strength of projected PFR methodology for providing improved optimal solution in diminishing the real power loss. Variables of the control obtained from after the optimization via PFR is within the limits.

\section{REFERENCES}

[1] O. Alsac, and B. Scott, "Optimal load flow with steady state security", IEEE Transaction. PAS, pp.745-751, 1973.

[2] K.Y. Lee, Y.M. Paru, J.L. Oritz -A united approach to optimal real and reactive power dispatch, IEEE Transactions on power Apparatus and systems, PAS-104, pp.1147-1153, 1985.

[3] A.Monticelli, M.V.F Pereira , and S. Granville, "Security constrained optimal power flow with post contingency corrective rescheduling", IEEE Transactions on Power Systems, PWRS-2, no.1, pp.175$182,1987$.

[4] DeebN, Shahidehpur S.M, Linear reactive power optimization in a large power network using the decomposition approach. IEEE Transactions on power system, vol.5, no.2, pp.428-435, 1990.

[5] E. Hobson ,'Network consrained reactive power control using linear programming, ' IEEE Transactions on power systems PAS -99 (4), pp 868-877, 1980

[6] K.Y. Lee, Y.M Park, and J.L Oritz, "Fuel -cost optimization for both real and reactive power dispatches", IEE Proc; 131C,(3), pp.85-93.

[7] M.K. Mangoli, and K.Y. Lee, "Optimal real and reactive power control using linear programming", Electr.Power Syst. Res, vol.26, pp.1-10, 1993.

[8] C.A. Canizares , A.C.Z.de Souza and V.H. Quintana, " Comparison of performance indices for detection of proximity to voltage collapse", vol. 11, no.3, pp.1441-1450, Aug 1996 .

[9] S.R.Paranjothi ,andK.Anburaja, "Optimal power flow using refined genetic algorithm", Electr.PowerCompon.Syst, vol.30, pp.1055-1063, 2002.

[10] D. Devaraj, and B. Yeganarayana, "Genetic algorithm based optimal power flow for security enhancement", IEE procGeneration.Transmission and. Distribution; 152, 6 November 2005.

[11] A.Berizzi, C. Bovo, M. Merlo, and M. Delfanti, "A ga approach to compare orpf objective functions including secondary voltage regulation," Electric Power Systems Research, vol.84, no.1, pp.187194, 2012.

[12] C.-F. Yang, G. G. Lai, C.-H. Lee, C.-T. Su, and G. W. Chang, "Optimal setting of reactive compensation devices with an improved voltage stability index for voltage stability enhancement," International Journal of Electrical Power and Energy Systems, vol.37, no.1, pp. 50 -57, 2012.

[13] P. Roy, S. Ghoshal, and S. Thakur, "Optimal var control for improvements in voltage profiles and for real power loss minimization using biogeography based optimization," International Journal of Electrical Power and Energy Systems, vol.43, no.1, pp.830-838, 2012.

[14] B. Venkatesh, G. Sadasivam, and M. Khan, "A new optimal reactive power scheduling method for loss minimization and voltage stability margin maximization using successive multi-objective fuzzy lp technique," IEEE Transactions on Power Systems, vol.15, no.2, pp. 844-851, may 2000.

[15] W. Yan, S. Lu, and D. Yu, "A novel optimal reactive power dispatch method based on an improved hybrid evolutionary programming technique," IEEE Transactions on Power Systems, vol. 19, no. 2, pp. 913 - 918, may 2004.

[16] W. Yan, F. Liu, C. Chung, and K. Wong, "A hybrid genetic algorithminterior point method for optimal reactive power flow," IEEE Transactions on Power Systems, vol.21, no.3, pp.1163-1169, Aug. 2006. 
[17] J. Yu, W. Yan, W. Li, C. Chung, and K. Wong, "An unfixed piecewiseoptimal reactive power-flow model and its algorithm for acdc systems," IEEE Transactions on Power Systems, vol.23, no.1, pp. 170-176, Feb. 2008.

[18] F. Capitanescu, "Assessing reactive power reserves with respect to operating constraints and voltage stability," IEEE Transactions on Power Systems, vol.26, no.4, pp.2224-2234, nov.2011.

[19] Z. Hu, X. Wang, and G. Taylor, "Stochastic optimal reactive power dispatch: Formulation and solution method," International Journal of Electrical Power and Energy Systems, vol.32, no.6, pp.615-621, 2010.

[20] Kargarian, M. Raoofat, and M. Mohammadi, "Probabilistic reactive power procurement in hybrid electricity markets with uncertain loads," Electric Power Systems Research, vol.82, no. , pp. 68-80, 2012.

[21] Li Zhang, Weijun Zhou, Donghui Li, "Global convergence of a modified Fletcher-Reeves conjugate gradient method with Armijo-type line search", Numerische Mathematik, October 2006, vol.104, no.4, pp.561-572

[22] K. Deb, A. Anand, and D. Joshi, A computationally efficient evolutionary algorithm for realparameter optimization. Evolutionary computation, Vol.10, No.4, pp.371-395, 2002.

[23] K. Deb, and M.Thakur, A new crossover operator for real coded genetic algorithms. Applied Mathematics and Computation, vol.188(1), pp.895-911, 2007.

[24] Q.H. Wu, Y.J.Cao, and J.Y. Wen. Optimal reactive power dispatch using an adaptive genetic algorithm. Int. J. Elect. Power Energy Syst. vol 20. pp.563-569, Aug 1998.

[25] B. Zhao, C. X. Guo, and Y.J. CAO.Multiagent-based particle swarm optimization approach for optimal reactive power dispatch. IEEE Trans. Power Syst. Vol.20, no.2, pp.1070-1078, May 2005.

[26] Mahadevan. K, Kannan P. S. "Comprehensive Learning Particle Swarm Optimization for Reactive Power Dispatch”, Applied Soft Computing, Vol.10, No.2, pp.641-52, March 2010.

[27] A.H. Khazali, M. Kalantar, "Optimal Reactive Power Dispatch based on Harmony Search Algorithm", Electrical Power and Energy Systems, vol.33, no.3, pp.684-692, March 2011.

[28] S. Sakthivel, M. Gayathri, V. Manimozhi, "A Nature Inspired Optimization Algorithm for Reactive Power Control in a Power System", International Journal of Recent Technology and Engineering (IJRTE), vol.2, no.1, pp.29-33, March 2013.

\section{BIOGRAPHIES}

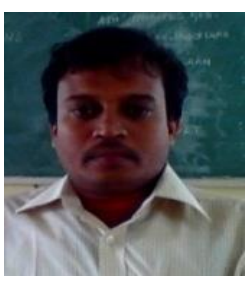

Kanagasabai Lenin has received his B.E., Degree, electrical and electronics engineering in 1999 from university of madras, Chennai, India and M.E., Degree in power systems in 2000 from Annamalai University, TamilNadu, India. Presently pursuing Ph.D. degree at JNTU, Hyderabad, India.

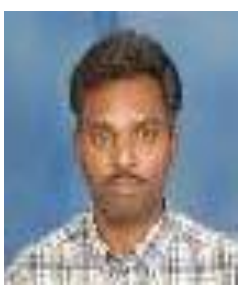

Bhumanapally Ravindhranath Reddy, Born on 3rd September,1969. Got his B.Tech in Electrical \& Electronics Engineering from the J.N.T.U. College of Engg., Anantapur in the year 1991. Completed his M.Tech in Energy Systems in IPGSR of J.N.T.University Hyderabad in the year 1997. Obtained his doctoral degree from JNTUA,Anantapur University in the field of Electrical Power Systems. Published 12 Research Papers and presently guiding 6 $\mathrm{Ph} . D$. Scholars. He was specialized in Power Systems, High Voltage Engineering and Control Systems. His research interests include Simulation studies on Transients of different power system equipment.

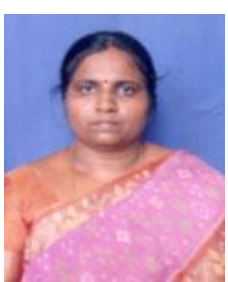

M. Surya Kalavathi has received her B.Tech. Electrical and Electronics Engineering from SVU, Andhra Pradesh, India and M.Tech, power system operation and control from SVU, Andhra Pradesh, India. She received her Ph.D. Degree from JNTU, Hyderabad and Post doc. From CMU - USA. Currently she is Professor and Head of the electrical and electronics engineering department in JNTU, Hyderabad, India and she has Published 16 Research Papers and presently guiding $5 \mathrm{Ph} . \mathrm{D}$. Scholars. She has specialized in Power Systems, High Voltage Engineering and Control Systems. Her research interests include Simulation studies on Transients of different power system equipment. She has 18 years of experience. She has invited for various lectures in institutes. 